\title{
doispontos:
}

\section{Corpo e ilegalismos}

\author{
Márcio Alves da Fonseca \\ marciofons@uol.com.br \\ Programa de Estudos Pós-graduados em Filosofia, Pontifícia Universidade Católica de São Paulo (PUC-SP), \\ São Paulo, SP, Brasil
}

\begin{abstract}
Resumo: Ao retomar o significado da noção de "ilegalismo" nos escritos de Foucault, especialmente a partir do curso La société punitive (1973), o artigo procura pensar alguns aspectos da implicação entre corpo, lei e resistência segundo a perspectiva do filósofo. A partir das distinções entre o ilegalismo de depredação e o ilegalismo de dissipação, que mostrarão de que modo este último terá como ponto de aplicação não o corpo da riqueza, mas o próprio corpo do trabalhador, sugere-se a potencialidade das análises de Foucault sobre os ilegalismos para se pensar nas relações entre o corpo, a lei, a norma e a resistência.
\end{abstract}

Palavras-chave: Michel Foucault; ilegalismo; lei; norma; corpo; resistência.

\section{Body and illegalisms}

\begin{abstract}
The article attempts to think about some aspects of the implication between body, law and resistance, according to the philosopher's perspective, while returns to the meaning of the notion of "illegalism" in Foucault's writings, especially from the course La société punitive (1973). From the distinctions between the illegalism of depredation and the illegalism of dissipation, which will show how the latter will have as its point of application not the body of wealth but the body of the worker itself, we suggest the potentiality of Foucault's analysis about illegalisms to think about the relations between the body, the law, the norm and the resistance.
\end{abstract}

Keywords: Michel Foucault; illegalism; law; norm; body; resistance.

Os encontros do corpo com a lei, nos escritos de Foucault, em geral revelam algo de trágico. O exemplo mais evidente desta ideia consiste no minucioso relato do suplício de Damiens, presente na abertura de Vigiar e punir. Ainda que imediatamente lembrado, devido ao detalhamento de uma narrativa que quase permite ver e ouvir o sofrimento imposto ao corpo de Damiens, este modo de encontro trágico do corpo com a lei não é único nos trabalhos do filósofo. Ele se faz presente inúmeras vezes e, em certo sentido, constitui um alerta consideravelmente repetido em seus livros e cursos: o par corpo-lei é violento, ou ainda, mais precisamente, o encontro do corpo com a lei faz sangrar, permite encarcerar, dá lugar ao adestramento, medicaliza o prazer, regula a vida. Assim, para além do corpo esquartejado de Damiens, perfilam-se, numerosos, outros corpos anônimos e comuns que adensam o conjunto daqueles cujos encontros do corpo com a lei se revela trágico.

Diante desta presença frequente, propomos refletir sobre uma forma de encontro entre o corpo e a lei, em Foucault, menos habitualmente considerada. Forma de encontro que não seria da ordem do embate 
impetuoso ou da apropriação, do adestramento ou da regulação, mas seria, sobretudo, da ordem da estratégia e do jogo. Forma de encontro que nos parece estar sugerida nas análises de Foucault sobre os ilegalismos.

\section{O QUE ESTÁ EM JOGO NO JOGO DOS ILEGALISMOS}

A noção de ilegalismo é introduzida por Foucault no curso do Collège de France de 1973, A sociedade punitiva, e terá um papel importante para a explicação, segundo uma perspectiva histórica, sobre o surgimento e a generalização da pena de prisão, associada à figura do delinquente como inimigo social e ao instrumento do exame como forma de determinação da verdade sobre os indivíduos.

Tanto em A sociedade punitiva quanto em Vigiar e punir, a noção de ilegalismo vem responder à dificuldade em se compreender a passagem da forma punitiva que tinha por cerne a correspondência precisa entre os crimes praticados e as penas com que eram punidos para a forma punitiva maciça e uniforme do sistema penitenciário do século XIX. A primeira delas refere-se à forma punitiva concebida no bojo da reforma humanista do direito penal na segunda metade do século XVIII; a segunda forma de punição, como se sabe, constitui-se na prisão.

De que modo, no início da época moderna, teria podido se implantar e difundir a tática punitiva do aprisionamento, no mesmo momento em que se formulava claramente, no âmbito da teoria do direito penal, a ideia do criminoso como inimigo social? A resposta a esta questão central da problematização realizada por Foucault acerca do surgimento e da generalização da forma punitiva do aprisionamento supõe a noção de ilegalismo.

A concepção do criminoso como inimigo público começa a ser formulada já início do século XVIII, com as análises dos fisiocratas acerca da delinquência, segundo a perspectiva das determinações dos processos econômicos (Cf. FOUCAULT, 1975, p. 104-105, 2013, p. 45-54). Nas análises destes economistas, a vadiagem é compreendida como a matriz geral de todos os crimes, contendo, assim, o embrião das outras formas de delinquência. A recusa ao trabalho representa, portanto, um peso para toda a sociedade, e aquele que se recusa a trabalhar coloca-se em posição de hostilidade perante ela. Declarando guerra contra a sociedade, o criminoso configura-se, então, como inimigo público.

Ora, diante desta figura do criminoso como inimigo social, a forma punitiva proposta pelos reformadores - que preveem uma correspondência detalhada entre os diferentes tipos de crime e os diferentes tipos de pena - é mais relevante e eficaz do que a punição que se configurará como a prática geral do aprisionamento. Se o crime é compreendido como uma agressão à sociedade, a punição deve, acima de tudo, proteger a sociedade contra seus agressores. Para tanto, deve modular, segundo a gravidade da agressão sofrida, a resposta a ser dada a fim de proteger-se e, ao mesmo tempo, impedir que outros inimigos semelhantes se formem em seu interior.

Por isso que, em princípio, a proporcionalidade entre os crimes e as penas - proposta pela teoria do direito penal em meados do século XVIII - responderia de forma mais eficaz à concepção do criminoso como inimigo social do que poderia fazê-lo algo como um sistema penitenciário.

Ainda assim, a partir do início do século XIX ocorre a generalização do sistema penitenciário como forma punitiva, não confirmando, no plano das práticas, aquela correspondência teórica entre a graduação das penas preconizada pelos reformadores e a ideia de crime como perigo público. 
Como compreender, então, que a forma do aprisionamento tenha podido se consolidar simultaneamente à noção de criminoso como inimigo público? Foucault encontrará essa resposta na análise sobre os ilegalismos.

Para o filósofo, são as transformações no regime dos ilegalismos que permitirão explicar a formação, na passagem do século XVIII ao século XIX, de uma "sociedade punitiva”, sociedade na qual “[...] o aparelho de Estado judiciário exerce [para além das funções de julgar os crimes e de aplicar as penas] funções corretivas e penitenciárias" (FOUCAULT, 2013, p. 143). A sociedade punitiva tem lugar, segundo Foucault, quando se tem “[...] um sistema penal que, pela primeira vez, é [também] um sistema penitenciário" (Cf. FOUCAULT, 2013, p. 143).

A explicação para este sistema unificado - penal/judiciário e, ao mesmo tempo, penitenciário - seria aparentemente simples: no final do século XVIII, no qual o crescimento e a instalação do modo de produção capitalista teriam provocado certo número de crises políticas, a vigilância política de uma plebe que se vê proletarizar implicaria a colocação em funcionamento de um novo aparelho repressivo, consistente em um novo sistema, ao mesmo tempo, judiciário e penitenciário (Cf. FOUCAULT, 2013, p. 144).

Entretanto, segundo Foucault, o mecanismo que teria levado à formação desse sistema punitivo unificado, caracterizador da sociedade punitiva, seria mais profundo e mais amplo do que a mera repressão à plebe sediciosa. O que, de fato, teria sido necessário gerir e controlar por meio do sistema penitenciário constitui um "fenômeno mais profundo e mais constante", dirá, do qual a revolta de um grupo específico é apenas um caso particular. Para Foucault, trata-se aqui do "ilegalismo popular" (Cf. FOUCAULT, 2013, p. 144).

Para uma primeira caracterização deste, o filósofo recorre a um exemplo colhido do estudo de Paul Bois, intitulado Camponeses do Oeste. Das estruturas econômicas e sociais às opções políticas após a época revolucionária em Sarthe (apud FOUCAULT, 2013, p. 156). Desse estudo, destaca aspectos da atuação dos tecelões da região de Maine. Para Foucault, este seria um exemplo interessante, pois se refere a uma profissão que rapidamente entraria no sistema capitalista de produção e que, no século XVIII, ainda se exercia na fronteira entre a cidade e o campo; além disso, ela teria sido uma das profissões mais livres até aquele momento, controlada apenas por alguns regulamentos emanados pelo controle geral de finanças.

Os tecelões da região estudada eram artesãos, cujas atividades eram controladas por ordenanças que definiam, por exemplo, a qualidade dos diferentes tecidos, o comprimento das peças, a marca própria do artesão. Estas operações eram objeto de certa vigilância e implicavam alguns direitos que a elas estavam correlacionados: o direito daqueles que produziam [os tecelões], o direito daqueles que comercializavam e o direito daqueles que compravam.

Desse modo, para escapar a esses controles, dos quais nem todos eram desfavoráveis aos interesses dos artesãos, pois alguns os protegiam e beneficiavam, estabelecia-se uma "ilegalidade de mão dupla". Tanto o comerciante, que devia comercializar, quanto o tecelão, que havia fabricado, "entendiam-se diretamente, para além dos regulamentos, para tentar deles escapar” (Cf. FOUCAULT, 2013, p. 145). Eles podiam, por exemplo, fazer contratos prévios, ao largo do mercado oficial. Assim, as partes, diretamente em contato, estabeleciam entre si certo número de relações comerciais que se constituíam, em certa medida, como leis do mercado. Pouco a pouco, dirá Foucault, o modo de produção capitalista se insere em um sistema propriamente artesanal, graças à prática desta dupla ilegalidade.

Essa forma de ilegalidade - o ilegalismo popular - é peculiar. Trata-se de um ilegalismo funcional, pois não constitui um obstáculo ao capital que está em vias de se industrializar, mas o favorece; ele não ataca a propriedade material, mas sim direitos de caráter feudal. Trata-se também de um ilegalismo sistemático, pois 
quase se constitui como um modo de funcionamento de toda a sociedade, na medida em que tangencia outros ilegalismos, pertinentes a outros grupos e atividades. Em terceiro lugar, trata-se de um ilegalismo ao mesmo tempo econômico e político pois, a cada vez que curto- circuita uma lei ou um regulamento, ataca a operação de poder e a instância regulamentadora que sustentam as regras econômicas. Por fim, trata-se de um ilegalismo oscilante, pois não realiza uma tomada de posição definitiva; nele, não se trata de se passar para o lado oposto da lei e praticar a ilegalidade, trata-se de estabelecer um jogo com a própria lei (Cf. FOUCAULT, 2013, p. 145-148).

Em síntese, para Foucault (2013, p. 148), “[...] não se pode compreender o funcionamento de um sistema penal, de um sistema de leis e de interdições, se não se interroga acerca do funcionamento positivo dos ilegalismos". Seria um "preconceito intelectual pensar que existe primeiramente interdições e posteriormente transgressões” (FOUCAULT, 2013, p. 148). E conclui: “[...] uma lei não funciona, não se aplica senão no interior de um campo de ilegalismo que é efetivamente praticado e que, de certo modo, a sustenta" (FOUCAULT, 2013, p. 149).

Pode-se, então, retornar à explicação proposta por Foucault para a constituição do sistema unificado penal/judiciário e ao mesmo tempo penitenciário - na passagem do século XVIII para o XIX. Ocorre aqui, tal como explicitado em Vigiar e punir, uma inversão no eixo segundo o qual os ilegalismos se organizavam (Cf. FOUCAULT, 1975, p. 98-106). Os ilegalismos populares eram organizados em torno das inobservâncias a direitos (como, por exemplo, a sonegação de impostos e o contrabando) que, se respeitados integralmente, constituiriam entraves ao funcionamento dos diferentes grupos em relação ao crescimento econômico. Como efeito desses mesmos ilegalismos, o aumento das riquezas favorecerá um deslocamento do alvo principal dos ilegalismos para os bens (como, por exemplo, o saque e a depredação), os quais a burguesia não tolerará. Em outros termos, o ilegalismo burguês, que convivia em simbiose com o ilegalismo popular, não mais suportará o funcionamento deste último, ou seja, o ilegalismo popular, em sua forma de ilegalismo de depredação, não será tolerado.

Assim, os aparelhos administrativo e policial serão transformados pela burguesia em aparelho judiciário encarregado de livrar-se do ilegalismo popular. É desse modo que o elemento do "penitenciário" - que funcionava no registro do não-legal - será integrado ao sistema da justiça.

Tem lugar, pois, a denúncia de todas as formas socializadas de ilegalismos e a identificação do indivíduo que pratica a ilegalidade como inimigo social; tem lugar também a aplicação sistemática, para cassar as ilegalidades, de meios como a infiltração, a denúncia, a delação; para além da lei como interdição, faz-se necessário ainda um suplemento dos códigos que venha completar e fazer esta lei funcionar, suplemento que terá a função de moralizar e regenerar; faz-se necessária também a separação efetiva, no interior dos grupos populares que praticam os ilegalismos, dos delinquentes e dos não-delinquentes (Cf. FOUCAULT, 2013, p. 152-153).

Tem-se aqui, dirá Foucault (2013, p. 167), " [...] a transformação do personagem do ilegalismo tolerado em um personagem que já é o delinquente monstruoso ao qual a penalidade, a criminologia, a psiquiatria do século XIX estarão implicadas". Eis a dualidade essencial do sistema penal em seu conjunto, a partir do século XIX: de um lado, esse sistema está apoiado em um discurso da penalidade pura, de outro, está organizado em torno de discursos e de instituições que pretendem corrigir e regenerar os indivíduos; de um lado o penal propriamente dito, do outro, o penitenciário (Cf. FOUCAULT, 2013, p. 182).

Este constitui o primeiro desenvolvimento da noção de ilegalismo em Foucault e se refere à caracterização do ilegalismo popular - enquanto ilegalismo de depredação - como elemento chave para a explicação do 
surgimento do sistema penitenciário moderno. Na sequência das aulas de $A$ sociedade punitiva, esta análise desdobra-se na consideração de um novo ilegalismo, cuja compreensão sugere-nos pensar nas relações entre o corpo e a lei de forma mais ampla, especialmente no que se refere a práticas de resistência.

\section{ILEGALISMO, CORPO E RESISTÊNCIA}

Este novo ilegalismo constitui-se como que a face reversa do ilegalismo de depredação, cujo ponto de aplicação era o corpo da riqueza como objeto de apropriação possível. O novo ilegalismo, por sua vez, terá como ponto de aplicação não propriamente o corpo da riqueza, mas o próprio corpo do trabalhador como força de produção. Trata-se do ilegalismo de dissipação, que terá lugar justamente no ponto de transformação da força corporal em força de trabalho e na integração dessa força no sistema de produção.

Concretamente, ele consistirá na recusa em consagrar o corpo e sua força ao aparelho de produção. Dentre as diversas formas que assumirá, Foucault põe quatro em destaque: a) a decisão pelo ócio, consistente na recusa do indivíduo em oferecer ao mercado de trabalho seus braços, sua força, enfim, seu corpo, tratando-se de subtrair o corpo à lei da livre concorrência e ao mercado; b) a irregularidade no trabalho ou o nomadismo, que seriam a recusa em consagrar o corpo e sua força lá onde se deve e no momento em que se deve, tratando-se aqui de dispersar as forças e decidir sobre o tempo e o lugar aos quais serão consagradas; c) a festa, que consiste em não esgotar a força corporal em tudo aquilo que pode torná-la utilizável, em outros termos, trata-se de desperdiçar sua força lá onde ela não será convertida em força de trabalho; d) por fim, a recusa da família, que consiste em não utilizar o corpo para a reprodução de suas forças na forma de uma família que eduque seus filhos de modo a renovar as forças de trabalho, recusa à família que pode se dar concretamente por meio do concubinato e da libertinagem.

Esta série de práticas são amplamente denunciadas por uma vasta literatura, que põe em funcionamento um discurso de moralização da classe trabalhadora, ora dissecando suas principais taras - como a intemperança, a imprevisibilidade, a anarquia das paixões, a prodigalidade, a falta de higiene, o mau uso do lazer - ora prescrevendo as condutas e os comportamentos que lhes seriam obrigatórios.

Configura-se, assim, o ambiente teórico, prático e legal no qual o ilegalismo de dissipação atuará. Ele assumirá, em todas as suas nuances, as formas variadas das ausências, dos atrasos, da preguiça, das festas, da libertinagem, do nomadismo, em uma palavra, de tudo aquilo que é da ordem da irregularidade.

Nesse horizonte de análise, Foucault sugere que caberia se fazer "toda uma história da preguiça", não no sentido de uma história dos lazeres, que seriam a maneira pela qual a ociosidade teria sido codificada e institucionalizada, mas uma história "[...] das maneiras pelas quais se escapou à obrigação ao trabalho, subtraiu-se à força de trabalho, evitou-se deixar-se reter e fixar pelo aparelho de produção" (FOUCAULT, 2013, p. 193-194).

A preguiça, como recusa coletiva e organizada ao trabalho no século XIX, se dá neste elemento do ilegalismo de dissipação, tal como é discutido por Foucault. E a caracterização da especificidade deste ilegalismo sugere a potencialidade das análises de Foucault sobre os ilegalismos para se pensar nas relações entre o corpo e a lei a partir da perspectiva da resistência.

O primeiro aspecto dessa especificidade é que o ilegalismo de dissipação se dá numa relação de reforço recíproco com o ilegalismo de depredação. Tanto mais as massas encontravam-se dissipadas e menos fixadas a pontos precisos do aparelho de produção, mais elas eram tendentes à depredação. Em contrapartida, 
quanto mais tendiam à depredação, mais tendiam a assumir uma forma de vida irregular, a fim de escaparem às sanções. Essa reciprocidade é que faz com que, quando se tentava controlar um desses ilegalismos, acabava-se por reforçar o outro. Na prática, por exemplo, todos os controles demasiado rígidos pelos quais se tentava vigiar as populações a fim de se frear a depredação, provocavam uma aceleração dos processos de mobilidade e nomadismo, ou seja, reforçava-se os ilegalismos de dissipação.

O segundo aspecto que marca a especificidade do ilegalismo de dissipação consiste no fato deste ser mais "perigoso" que o ilegalismo de depredação, pois podia assumir formas coletivas e difundir-se mais facilmente. Ele não supõe formas de organização precisas e também não supõe a formação de circuitos organizados - como, por exemplo, os esquemas de recebimento e de revenda de mercadorias - como no caso da depredação, mas consiste em modos de existência que remetem a escolhas, podendo assumir facilmente formas mais ou menos coletivizadas.

Em terceiro lugar, enquanto o ilegalismo de depredação regride no curso do século XIX, devido à aplicação de formas mais regulares de controle, o ilegalismo de dissipação, que parecia mais brando e mais cotidiano, durante o mesmo período, terá uma extensa fortuna política e acarretará graves perigos à riqueza burguesa. As dificuldades em controlá-lo serão muito maiores. Ao constituir-se como irregularidades, e não propriamente como infrações, ele se espalha em um nível infralegal.

A quarta especificidade do ilegalismo de dissipação consiste no fato de ser menos objeto de medo do que objeto de reprovação, uma vez que ele não agredia diretamente o corpo da riqueza, constituindo-se antes como uma deficiência no ganho da atividade produtiva. E os objetos e mecanismos dessa reprovação referiam-se àquilo que consistia, quase que invariavelmente, à imoralidade operária.

Finalmente, o quinto aspecto caracterizador do ilegalismo de dissipação refere-se à forma pela qual teria sido possível controlar a irregularidade por ele representada e promovida. Esse controle, segundo Foucault, supunha uma moralização da penalidade, mas supunha igualmente uma engrenagem mais fina e reticulada do que a engrenagem penal propriamente dita. Essa forma espraiada de controle se deu por meio de um mecanismo de penalização da própria existência. Por isso, para controlar esse ilegalismo, foi necessário introduzir no corpo social prolongamentos para-penais.

No horizonte da genealogia do poder realizada por Foucault, as especificidades do ilegalismo de dissipação - ilegalismo cujo ponto de aplicação era o próprio corpo do trabalhador e que se constituiu como que a outra face do ilegalismo de depredação, cujo ponto de aplicação era o corpo da riqueza - permitirão ao filósofo situar o corpo não apenas no elemento da lei e de seus aparelhos de interdição e de punição, mas situá-lo, sobretudo, no elemento poroso e relacional constituído pela norma, obrigando-nos a pensar de modo inteiramente diferente a própria resistência.

Os ilegalismos de dissipação, na passagem do século XVIII para o século XIX, demandarão um sistema punitivo extrajudiciário que é graduado, contínuo, cumulativo e que se exerce ao longo de toda a existência individual. Trata-se de uma "[...] trama ininterrupta que prolonga a justiça na vida cotidiana" (Cf. FOUCAULT, 2013, p. 199). Já estão esboçadas aqui, portanto, as análises que serão desenvolvidas em Vigiar e punir acerca dos mecanismos da disciplina dos corpos. A sociedade punitiva, constituída nestes termos, torna-se possível mediante um sistema de vigilância exaustivo, mediante a organização de um sistema minucioso de controles e mediante a constituição de um saber permanente sobre os indivíduos, saber que tem a forma do exame. 
Desse modo, o estudo da "sociedade punitiva", realizado no curso de 1973, bem como o estudo da "sociedade disciplinar", realizado em Vigiar e punir, têm um de seus pontos sustentação mais importantes na análise dos ilegalismos, em especial, do ilegalismo de dissipação.

A partir da caracterização deste ilegalismo, presente no início da época moderna, Foucault situará o corpo - considerado em suas relações com a lei até este momento, mas, sobretudo, considerado em suas relações com a lei e com a norma a partir de então - no cerne tanto dos mecanismos de poder que caracterizam o limiar dessa época quanto no fundamento das formas de resistência que poderão opor-se a estes mecanismos.

O ilegalismo, tal como Foucault o apresenta, circula entre a lei e a norma. Por isso, nas implicações entre o corpo e a lei, o ilegalismo de dissipação do início do século XIX exercia um papel de resistência, porque subtraía o corpo da ordem produtiva, dissipava a sua energia, tornava-o nômade em relação aos espaços em que sua utilidade era requerida. Ao fazê-lo, exercia, ao mesmo tempo, um papel de resistência às implicações entre o corpo e a norma, porque instaurava a irregularidade e o desvio, lá onde estavam dados a medida e os critérios de normalidade.

Em Foucault, a principal ideia que está relacionada à noção de ilegalismo é aquela de jogo: jogo entre certo número de práticas, jogo entre certo número de prescrições legais e ilegalidades, entre comportamentos normais e irregularidades. O ilegalismo supõe a constituição de jogos simultâneos com a lei e com a norma. Por isso que, na época da norma, o encontro do corpo com a lei poderá passar menos pelo gládio, pelo confronto direto (e, portanto, pelo trágico), e deverá passar mais pela estratégia, pelo jogo (e, portanto, pela banalidade do cotidiano).

Na intersecção entre o gládio e a estratégia, entre o confronto direto e o jogo, entre o trágico e o cotidiano, as análises de Foucault sobre os ilegalismos sugere, então, a necessidade de pensarmos diferentemente as formas possíveis de resistência. Sejam quais forem estas formas, elas se constituirão no contexto de um jogo móvel e inacabado, e terão de haver-se invariavelmente com os encontros entre o corpo, a lei e a norma.

\section{REFERÊNCIAS}

FOUCAULT, M. 1975. Surveliller et punir: naissance de la prison. Paris: Gallimard. .2013. La société punitive: cours au Collège de France 1972-1973. Paris: EHESS/Gallimard/Seuil. 